\title{
Permeability and Morphology of Skeletal Muscle Capillaries in Type 1 (Insulin-Dependent) Diabetes Mellitus
}

\author{
H. Leinonen ${ }^{1}$, E. Matikainen ${ }^{2}$ and J.Juntunen ${ }^{3}$ \\ ${ }^{1}$ First Department of Medicine and 2 Department of Neurology, University Central Hospital, and \\ ${ }^{3}$ Neuroscience Group, Institute of Occupational Health, Helsinki, Finland
}

Summary. Muscle blood flow and capillary diffusion capacity were determined in 21 Type 1 (insulin-dependent) diabetic patients and in 12 age-matched healthy subjects by measuring the simultaneous clearance of ${ }^{133}$ xenon and ${ }^{131}$ iodide from hyperaemic anterior tibial muscle. Blood flow was significantly lower (mean $\pm \mathrm{SD}: 46.7 \pm 14.1$ versus $59.4 \pm 12.9 \mathrm{ml}$ $100 \mathrm{~g}^{-1} \min ^{-1}, p<0.02$ ) and capillary diffusion capacity was significantly greater (mean $\pm \mathrm{SD}$ : $8.0 \pm 2.1$ versus $5.9 \pm 1.3 \mathrm{~mol} / \mathrm{min}, p<0.005$ ) in the diabetic patients than in the control subjects. Ultrastructural dimensions and density of capillaries in the gastrocnemius muscle of 11 diabetic patients and six control subjects were also studied. Diabetic and control capillaries did not differ in total capillary area. Compared with normal capillaries, the percentage area of basement membrane and the apparent basement membrane thickness were significantly greater $(1.21 \pm 0.6$ versus $0.78 \pm 0.2 \mu, p<0.05)$ in diabetic capillaries, while there were no significant differences in luminal, endothelial and pericytial areas. There was no difference in capillary density between the two groups. No correlation was found between basement membrane thickness and capillary diffusion capacity in the diabetic patients. We conclude that the greater capillary diffusion capacity is due to increased permeability of diabetic capillaries, and that the basement membrane is probably not ratelimiting in the transcapillary transport of hydrophilic substances in diabetic subjects.

Key words: Basement membrane, capillaries, capillary permeability, diabetes mellitus, iodide, morphology, muscle blood flow, muscle tissue, xenon.
Basement membrane thickening of skeletal muscle capillaries in diabetic subjects has been reported by many investigators [1-5]. The aetiology, prevalence and significance of this thickening remain, however, controversial [6-8], and it does not constitute a lesion which is specific for diabetes, as it is also found with advancing age [4] and in other conditions, including inflammatory myopathies [9], congestive heart failure [10], and intermittent claudication [11]. These findings have encouraged many researchers to characterize and quantify these lesions physiologically, but the functional significance of diabetic angiopathy is still unsolved $[6,12]$. Using different methods, microvascular permeability for proteins, albumin and IgG [13], the hydrophilic ions of sodium, iodine and chromium EDTA [14-17] was found to be increased. In addition, by using the ${ }^{133}$ xenon clearance method, muscle blood flow was found to be unchanged $[14,15,18]$ or reduced $[17,19]$ in long-term diabetic patients when compared with control subjects.

To date, however, there have been no attempts to study the relationship between the morphological and the functional alterations which accompany diabetes in the same group of patients. The present study was designed to estimate muscle blood flow and capillary diffusion capacity in diabetic patients by measuring the local clearance of ${ }^{133}$ xenon and ${ }^{131} \mathrm{I}^{-}$-isotopes, and to measure concomitantly the ultrastructural dimensions and density of capillaries in diabetic muscle.

\section{Subjects and Methods}

Twenty-one Type 1 (insulin-dependent) diabetic out-patients, aged 24-54 years (mean 38 years) were studied ( 12 males and nine females). The duration of their diabetes was 2-22 years (mean 14 years). They were all normotensive and had good metabolic control 
Table 1. Clinical details of 21 Type 1 (insulin-dependent) diabetic patients studied

\begin{tabular}{|c|c|c|c|c|c|c|c|c|}
\hline $\begin{array}{l}\text { Number of } \\
\text { patients }\end{array}$ & $\begin{array}{l}\text { Sex } \\
\text { (male: } \\
\text { female) }\end{array}$ & $\begin{array}{l}\text { Age } \\
\text { (years) }\end{array}$ & $\begin{array}{l}\text { Body } \\
\text { weight } \\
(\mathrm{kg})\end{array}$ & $\begin{array}{l}\text { Body } \\
\text { weight } \\
\text { ( } \% \text { of ideal) }\end{array}$ & $\begin{array}{l}\text { Duration of } \\
\text { diabetes } \\
\text { (years) }\end{array}$ & Retinopathy ${ }^{\mathrm{a}}$ & $\begin{array}{l}\text { Nephropathy } \\
\text { (No. of patients) }\end{array}$ & Neuropathy ${ }^{c}$ \\
\hline \multicolumn{9}{|c|}{ Muscle biopsy performed } \\
\hline 11 & $6: 5$ & $\begin{array}{c}39 \pm 10 \\
(29-54)\end{array}$ & $\begin{array}{c}66 \pm 9 \\
(52-76)\end{array}$ & $\begin{array}{l}95 \pm \quad 6 \\
(82-102)\end{array}$ & $\begin{array}{c}13 \pm 7 \\
(2-22)\end{array}$ & 6 & 2 & 7 \\
\hline \multicolumn{9}{|c|}{ Muscle biopsy not performed } \\
\hline 10 & $6: 4$ & $\begin{array}{c}36 \pm 10 \\
(24-54)\end{array}$ & $\begin{array}{c}69 \pm 11 \\
(50-78)\end{array}$ & $\begin{array}{c}98 \pm \quad 7 \\
(85-108)\end{array}$ & $\begin{array}{c}14 \pm 5 \\
(5-21)\end{array}$ & 4 & 1 & 3 \\
\hline
\end{tabular}

Results expressed as mean $\pm \mathrm{SD}$; range in parentheses

${ }^{a}$ Mild to moderate non-proliferative retinopathy

${ }^{\mathrm{b}}$ Positive Albustix with normal serum creatinine levels

${ }^{c}$ Diagnosis based on impaired light touch, pain and vibratory perception and abnormal reflexes in upper and lower limbs

at the time of the study (blood glucose $<9 \mathrm{mmol} / \mathrm{l}$, no ketonuria and glycosuria $<5 \mathrm{~g} /$ day). None had heart disease or clinical evidence of peripheral vascular disease. The clinical details of these patients are given in Table 1. Twelve healthy volunteers, aged 22-53 years (mean 32 years), served as a control group for the clearance measurements. Informed consent was obtained from all subjects for the study, which was approved by the Ethical Committee of the University Central Hospital, Helsinki, Finland.

Muscle blood flow and capillary diffusion capacity measurements were made in the anterior tibial muscle of both legs in all diabetic and control subjects. The detailed descriptions of the methods employed are described elsewhere [20]. In brief, the clearance rates were recorded with the use of ${ }^{133}$ Xenon $(50-70 \mu \mathrm{Ci})$ and ${ }^{13 !} \mathrm{I}^{-}$ $(10-20 \mu \mathrm{Ci})$ dissolved in $0.1 \mathrm{ml}$ of isotonic saline introduced via a narrow gauge needle into the muscle, which was made hyperaemic with ischaemic exercise until exhaustion (for at least $3 \mathrm{~min}$ ). The calculations of muscle blood flow and capillary diffusion capacity and their theoretical bases are also discussed elsewhere in detail $[15,20,21]$. The mean value from both legs was used in the calculations, except for three diabetic subjects, in whom exceptionally low unilateral muscle blood flow values were observed. This was probably an artifact due to injection into fatty tissue; therefore, only the higher value was used for the calculations.

The muscle biopsies were taken from the gastrocnemius muscles of 11 diabetic patients, of whom seven had neuropathy. All the patients with neuropathy had symmetric sensory-motor polyneuropathy, and, in addition, two had autonomic neuropathy. They were aged 29-54 years (mean 40 years) and their duration of diabetes was 2-22 years (mean 13 years). The control biopsy material was taken from the gastrocnemius muscle of six non-diabetic patients with no evidence of neuromuscular disease based on clinical, histopathological, neurophysiological and other laboratory examinations. An oral glucose tolerance test was normal in all control biopsy subjects (fasting blood glucose $<5 \mathrm{mmol} / \mathrm{l}$, at $2 \mathrm{~h}<7 \mathrm{mmol} /$ 1). They were aged $48-57$ years (mean 52 years), their mean weight was $64 \pm 9 \mathrm{~kg}$ (range $50-81 \mathrm{~kg}$ ) and body weight (percentage of ideal) was $95 \pm 7 \%$ (range $88-105 \%$ ).

\section{Morphological Studies}

Only one tissue block was studied in each patient. However, when preparing the specimens for electron microscopy, special care was taken to obtain perfect cross sections, i. e. that the longitudinal axis of the muscle fibres and capillaries was perpendicular to the plane of section. The muscle biopsy was performed by sharp dissection under direct vision and in each case a large muscle sample was taken in order to detect the direction of the muscle fibres. The muscle samples were fixed in glutaraldehyde-osmium tetroxide solution, followed by embedding in Epon-812 (Ladd Research Industries, Burlington, Vermont, USA) and stained with uranyl acetate and lead citrate. The specimens were carefully oriented in Epon- 812 with the aid of a dissecting microscope, enabling us to check the direction of the muscle fibres and correct their orientation, if needed. The capillaries were predominantly circular in shape, thus indicating that cross sections were obtained. All non-circular capillaries including any collapsed vessels were discarded. Thereafter, 6-17 capillaries per specimen were photographed at a primary magnification of 5000 (final magnification 14,800). Planimetry was used to measure the following in each capillary: (1) the total capillary area, including basement membrane, (2) the basement membrane area and (3) luminal, endothelial and pericytial areas. The results obtained are stated as a percentage of the total capillary area. Using this method, the values are unaffected by the angle of the section [22]. To eliminate the effect of any collapsing of the capillaries, the relative size of the basement membrane was also expressed as the average apparent basement membrane thickness, obtained by dividing the basement membrane area by the external perimeter of the endothelial cell measured with a planimeter. Two independent investigators tested the reproducibility of the areas measured with the planimeter with repeated measurements and against a standard area. A $95 \%$ confidence limit was obtained.

The number of capillaries per $\mathrm{mm}^{2}$ of muscle was calculated from three Epon-embedded, semi-thin transverse sections stained with Toluidine blue. The capillaries could easily be distinguished from other structures by light microscopy at a magnification of 400 . The number of capillaries per $\mathrm{mm}^{2}$ was calculated according to the method of Brodal et al. [23].

Student's t-test was used for statistical assessment of the differences between groups in the clearance studies. Because of the skewed distribution of the morphometrical measurements, nonparametric methods (Mann-Whitney's and Kolmogorov-Smirnov's tests) were employed in studying the differences between diabetic and control capillaries, and in each individual, medians were used instead of mean values. Two variable regression estimates were used for correlative studies of the different variables.

\section{Results}

The mean muscle blood flow and capillary diffusion capacity values for the diabetic and control subjects are presented in Table 2. The maximum anterior tibial muscle blood flow was significantly lower in the dia- 
betic patients $(p<0.02)$. Seven of the 21 diabetic patients had muscle blood flow values below $35 \mathrm{ml}$ $100 \mathrm{~g}^{-1} \mathrm{~min}^{-1}$, which is considered as the lower limit of normal maximum blood flow [14]. The rate constant $\left(\mathrm{k}_{\mathrm{I}}\right)$ and capillarly diffusion capacity for ${ }^{131} \mathrm{I}^{-}$ were both significantly increased in the diabetic patients. The average increment of capillary diffusion capacity was $36 \%$. The muscle blood flow, $\mathrm{k}_{\mathrm{I}}$ and capillary diffusion capacity did not differ significantly when the diabetic patients were divided into those with and without neuropathy (Table 3). However, five of the seven patients with a pathologically low muscle blood flow had neuropathy. In the diabetic patients, no significant correlations were found between muscle blood flow and capillary diffusion capacity. In addition, neither correlated with age or duration of diabetes.

The mean total capillary area did not differ significantly between the diabetic and control subjects (Table 4). There was, however, considerable variation in diabetic and control capillaries with regard to their size, basement membrane thickness, and luminal, endothelial and pericytial areas. Diabetic capillaries were characterized by remarkable, uniform thickening of the basement membrane, but in rare cases there was replication into two or more layers. The mean basement membrane area as a percentage of the total capillary area and the average apparent basement membrane thickness were both significantly greater in the diabetic capillaries $(p<0.05)$, while there were no significant differences in endothelial, luminal and pericytial areas in the same capillaries (Table 4). Furthermore, in the diabetic patients, no significant correlation was found between basement membrane thickening and age and the duration of diabetes. In addition, regression analyses showed no relationship between muscle blood flow, capillary diffusion capacity and the degree of basement membrane thickening.

The average numbers of capillaries per $\mathrm{mm}^{2}$ in muscle were $311 \pm 25$ and $325 \pm 37$ (mean \pm SEM) in the diabetic and control groups, respectively. This difference was not statistically significant.

\section{Discussion}

Typical pathophysiological findings in diabetes of long duration include decreased maximal blood flow and increased capillary permeability in the anterior

Table 2. Muscle blood flow, rate constant for ${ }^{131} \mathrm{I}^{-}\left(\mathrm{k}_{\mathrm{I}}\right)$ and capillary diffusion capacity in diabetic patients and control subjects

\begin{tabular}{llll}
\hline & $\begin{array}{l}\text { Muscle blood flow } \\
\left(\mathrm{ml} 100 \mathrm{~g}^{-1} \mathrm{~min}^{-1}\right)\end{array}$ & $\begin{array}{l}\mathrm{k}_{\mathrm{I}} \\
\left(\mathrm{min}^{-1}\right)\end{array}$ & $\begin{array}{l}\text { Capillary } \\
\text { diffusion } \\
\text { capacity } \\
(\mathrm{mol} / \mathrm{min})\end{array}$ \\
\hline $\begin{array}{l}\text { Diabetic } \\
\text { patients } \\
(n=21)\end{array}$ & $46.7 \pm 14.1^{\mathrm{a}}$ & $0.45 \pm 0.11^{\mathrm{b}}$ & $8.0 \pm 2.1^{\mathrm{c}}$ \\
$\begin{array}{l}\text { Control } \\
\text { subjects } \\
(n=12)\end{array}$ & $59.4 \pm 12.9$ & $0.35 \pm 0.07$ & $5.9 \pm 1.3$ \\
\hline
\end{tabular}

Results expressed as mean $\pm \mathrm{SD}$

${ }^{\mathrm{a}} p<0.02 ;{ }^{\mathrm{b}} p<0.01 ;{ }^{\mathrm{c}} p<0.005$; diabetic versus normal subjects (unpaired Student's t-test)

Table 3. Results for diabetic subjects with and without neuropathy

\begin{tabular}{llll}
\hline & $\begin{array}{l}\text { Muscle blood } \\
\text { flow }\left(\mathrm{ml} 100 \mathrm{~g}^{-1}\right. \\
\left.\mathrm{min}^{-1}\right)\end{array}$ & $\begin{array}{l}\mathrm{k}_{\mathrm{l}} \\
\left(\mathrm{min}^{-1}\right)\end{array}$ & $\begin{array}{l}\text { Capillary } \\
\text { diffusion } \\
\text { capacity } \\
(\mathrm{mol} / \mathrm{min})\end{array}$ \\
\hline $\begin{array}{l}\text { Patients with } \\
\text { neuropathy } \\
\begin{array}{l}(n=10) \\
\text { Patients without } \\
\text { neuropathy } \\
(n=11)\end{array}\end{array}$ & $44.0 \pm 15.2$ & $0.43 \pm 0.08$ & $7.6 \pm 1.5$ \\
\hline
\end{tabular}

Results expressed as mean \pm SD

$\mathrm{k}_{\mathrm{l}}=$ rate constant for ${ }^{131} \mathrm{I}$

The differences between patients with and without neuropathy were not significant (Student's $t$-test)

Table 4. Morphometric analysis of capillary dimensions in diabetic and control subjects

\begin{tabular}{|c|c|c|c|c|c|c|c|}
\hline & $\begin{array}{l}\text { Age } \\
\text { (years) }\end{array}$ & $\begin{array}{l}\text { Capillary } \\
\text { area }\left(\mu^{2}\right)\end{array}$ & $\begin{array}{l}\text { Average basement } \\
\text { membrane thick- } \\
\text { ness }(\mu)\end{array}$ & $\begin{array}{l}\text { Basement membrane } \\
\text { area as fraction of } \\
\text { capillary area }(\%)\end{array}$ & $\begin{array}{l}\text { Luminal } \\
\text { fraction of } \\
\text { capillary } \\
\text { area }(\%)\end{array}$ & $\begin{array}{l}\text { Endothelial } \\
\text { fraction of } \\
\text { capillary } \\
\text { area }(\%)\end{array}$ & $\begin{array}{l}\text { Pericyte } \\
\text { area as } \\
\text { fraction of } \\
\text { capillary } \\
\text { area }(\%)\end{array}$ \\
\hline $\begin{array}{l}\text { Diabetic patients } \\
(n=11)\end{array}$ & $\begin{array}{c}40 \pm 10 \\
(29-54)\end{array}$ & $38.0 \pm 9.6$ & $1.21 \pm 0.49$ & $48.5 \pm 10.5$ & $29.2 \pm 7.0$ & $19.5 \pm 5.0$ & $5.7 \pm 1.8$ \\
\hline $\begin{array}{l}\text { Control subjects } \\
(n=6)\end{array}$ & $\begin{array}{c}52 \pm 4 \\
(48-57)\end{array}$ & $36.9 \pm 8.1$ & $0.78 \pm 0.19$ & $39.5 \pm 6.2$ & $32.0 \pm 5.4$ & $23.2 \pm 3.2$ & $5.7 \pm 1.7$ \\
\hline
\end{tabular}

Results expressed as mean $\pm \mathrm{SD}$; range in parentheses

Total number of capillaries studied in the diabetic patients was 133 and in the control subjects $56 ;{ }^{\mathrm{a}} p<0.05$ diabetic versus control subjects (Mann-Whitney and Kolmogorov-Smirnov tests) 
tibial muscle. The main morphological findings are marked basement membrane thickening without changes in other components of the capillary and no change in muscle capillary density.

The pronounced basement membrane thickening found in this study of diabetic patients is consistent with previous results obtained using similar methods [3]. When studying alterations in capillary morphology and comparing diseased and normal subjects, it is essential that the groups of subjects studied are comparable with respect to their ages, site of biopsy and histological methods, because the results, particularly for basement membrane thickness, are substantially affected by these variables [6]. In the present study, the muscle biopsies were taken from the same site in the gastrocnemius muscle and the staining and other processing techniques were similar in all cases. The basement membrane values in the control subjects were greater than those previously reported by our laboratory [11]. This increase is most likely due to the higher mean age of the control subjects, as basement membrane thickness is known to increase with age [4]. For the same reason, the differences between diabetic and control basement membranes would probably have been even greater if the groups were perfectly matched for age.

The present study confirmed previous observations of increased capillary permeability in patients with diabetes of long duration when compared with normal subjects. Earlier studies demonstrated increased permeability both for high molecular-weight proteins [13], and for small hydrophilic molecules in the leg $[14,15,17]$ and in the forearm [16]. At present there is no satisfactory explanation for this increased capillary permeability. However, there are two possible mechanisms: (1) an increase in capillary surface area, (2) greater capillary permeability per unit of capillary surface area. Alpert et al. [17] found that the capillary diffusion capacity is increased without a concomitant increase in the capillary filtration coefficient, which is considered to be a measure of capillary surface area. Other studies showed that forearm capillary filtration coefficient is, in fact, lower in early diabetes than in control subjects $[24,25]$. However, forearm capillary filtration coefficient tends to increase significantly with duration, and is largely due to the contribution of connective tissue [25]. Morphological studies have not supported the possibility that the muscle capillary surface area in diabetes is increased [26]. The number of capillaries per $\mathrm{mm}^{2}$ of muscle tends to give a good indication of the average distance of diffusion, provided that the same muscle groups are studied with identical methods. The present study and that of Norton [26] did not find any differences in capillary density between diabetic and normal muscle. On the whole, there is, in our opinion, no consistent evidence that the increased capillary permeability is due to increased microvascular area.

Previous studies have suggested that the increased capillary diffusion capacity in diabetics is due to an abnormal permeability of the capillary wall $[13,16$, 17]. There are multiple pathways for different molecules to pass through capillary walls, with the intercellular junctions playing a key role in the transport of water and small hydrophilic substances and probably also of larger molecules, such as proteins [27]. The role of the basement membrane in this process remains unclear, but it seems to be of minor significance. In the present study we could find no relationship between increased capillary diffusion capacity and basement membrane thickness in the diabetic patients. Furthermore, the diffusing properties of muscle capillaries were found to be normal in other diseases, such as Duchenne muscular dystrophy, which are accompanied by basement membrane changes [28].

Acknowledgements. This study was supported by the Foundation for Diabetes Research, Finland, the Paulo Foundation, Finland, and the Paavo I. Ahvenainen Foundation, Finland (Dr. H. Leinonen).

\section{References}

1. Zacks SI, Pegues JJ, Elliott FA (1962) Interstitial muscle capillaries in patients with diabetes mellitus: a light and electron microscope study. Metabolism 11:381-393

2. Siperstein MD, Unger RH, Madison LL (1968) Studies of capillary basement membranes in normal subjects, diabetic, and prediabetic patients. J Clin Invest 47: 1973-1999

3. Vracko R (1970) Skeletal muscle capillaries in diabetics: a quantitative analysis. Circulation $41: 271-284$

4. Kilo C, Vogler N, Williamson JR (1972) Muscle capillary basement membrane changes related to aging and to diabetes mellitus. Diabetes 21:881-905

5. Danowski TS, Fisher ER, Khurana RC, Nolan S, Stephan T (1972) Muscle capillary basement membrane in juvenile diabetes mellitus. Metabolism 21: 1125-1132

6. Williamson JR, Kilo C (1977) Current status of capillary basement-membrane disease in diabetes mellitus. Diabetes 26: $65-73$

7. Gundersen HJG, Østerby R, Lundbaek K (1978) The basement membrane controversy. Diabetologia 15:361-363

8. Siperstein MD, Feingold KR, Bennett PH (1978) Hyperglycaemia and diabetic microangiopathy. Diabetologia 15: $365-367$

9. Jerusalem F, Rakusa M, Engel AG, MacDonald RD (1974) Morphometric analysis of skeletal muscle capillary ultrastructure in inflammatory myopathies. J Neurol Sci 23: 391-402

10. Longhurst J, Capone RJ, Zelis R (1975) Evaluation of skeletal muscle capillary basement membrane thickness in congestive heart failure. Chest 67: 195-198

11. Mäkitie J (1977) Skeletal muscle capillaries in intermittent claudication. Arch Pathol Lab Med 101: 500-503

12. McMillan DE (1978) Diabetic angiopathy - its lessons in vascular pathology. Am Heart J 96: 401-406 
13. Parving HH, Rossing N (1973) Simultaneous determination of the transcapillary escape rate of albumin and $\mathrm{IgG}$ in normal and long-term juvenile diabetic subjects. Scand J Clin Lab Invest 32: 239-244

14. Trap-Jensen J, Alpert JS, Del Rio G, Lassen NA (1967) Capillary diffusion capacity for sodium in skeletal muscle in longterm juvenile diabetes mellitus. Acta Med Scand Suppl 476: $135-146$

15. Trap-Jensen J, Lassen NA (1968) Increased capillary diffusion capacity for small ions in skeletal muscle in long-term diabetics. Scand J Clin Lab Invest $21: 116-122$

16. Trap-Jensen J (1970) Increased capillary permeability to ${ }^{131} \mathrm{Io}-$ dide and ${ }^{51}$ CrEDTA in exercising forearm of long-term diabetics. Clin Sci 39:39-49

17. Alpert JS, Coffman JD, Balodimos MC, Koncz L, Soeldner JS (1972) Capillary permeability and blood flow in skeletal muscle of patients with diabetes mellitus and genetic prediabetes. $\mathrm{N}$ Engl J Med 286: 454-460

18. Munck $O$, Lindbjerg IF, Binder C, Lassen NA, Trap-Jensen J (1966) Skeletal muscle blood flow in diabetic patients determined by intramuscular injection of Xenon-133. Diabetes 15: 323-326

19. Christensen JN (1968) Muscle blood flow, measured by Xenon133 and vascular calcifications in diabetics. Acta Med Scand 183: $449-454$

20. Leinonen H, Salminen S, Peltokallio P (1978) Capillary permeability and maximal blood flow in skeletal muscle in athletes and non-athletes measured by local clearances of ${ }^{133} \mathrm{Xe}$ and ${ }^{13 \mathrm{I}} \mathrm{I}^{-}$. Scand $\mathbf{J}$ Clin Lab Invest 38: 223-227

21. Lassen NA, Trap-Jensen J (1968) Theoretical considerations on measurement of capillary diffusion capacity in skeletal muscle by the local clearance method. Scand J Clin Lab Invest 21: $108-115$

22. Vracko R (1970) Skeletal muscle capillaries in nondiabetics: A quantitative analysis. Circulation $41: 285-297$

23. Brodal P, Ingjer F, Hermansen L (1977) Capillary supply of skeletal muscle fibers in untrained and endurance-trained men. Am J Physiol 232: H705-712

24. Poulsen HL, Nielsen SL (1976) Water filtration of the forearm in short- and long-term diabetes mellitus. Diabetologia 12: $437-440$

25. Katz MA, Janjan N (1978) Forearm hemodynamics and responses to exercise in middle-aged adult-onset diabetic patients. Diabetes 27: 726-731

26. Norton WL (1970) Comparison of the microangiopathy of systemic lupus erythematosus, dermatomyositis, scleroderma, and diabetes mellitus. Lab Invest 22:301-308

27. Renkin EM (1977) Multiple pathways of capillary permeability. Circ Res 41: 735-743

28. Leinonen H, Juntunen J, Somer H, Rapola J (1979) Capillary circulation and morphology in Duchenne muscular dystrophy. Eur Neurol 18:249-254

Received: 12 September 1980

and in revised form: 2 November 1981

Dr. H. Leinonen

First Department of Medicine

University Central Hospital

Haartmaninkatu 4

SF-00290 Helsinki 29, Finland 